\section{POR UMA GEOGRAFIA DA CRISE?}

Sinais de uma sociedade em crise se avolumam por toda parte e a sua sensação se vai generalizando. Promotores de uma vasta bibliografia ${ }^{1}$ sobre a recente corrida mundial por terras falam de uma "convergência de crises" gerando narrativas diversas: crise ambiental, crise do trabalho, crise financeira, crise de políticas do Estado nacional, etc. A lenta recuperação da economia mundial, após a crise financeira iniciada com a derrocada da bolha imobiliária norte-americana, já dá sinais de esgotamento e analistas sugerem a aproximação de uma nova grande quebra. Ondas de refugiados tentam escapar de guerras civis mas se deparam com muros por toda a parte. $\mathrm{O}$ militarismo ressurge como tentativa desesperada de controle populacional e canalização de anseios por parcelas da população temendo ser elas mesmas jogadas às fileiras dos descartáveis. As catástrofes ambientais recorrentes já não encontram mais saídas confiáveis em discursos jurídicos ou científicos que prometam qualquer solução duradoura. Mesmo a suposta normalidade do cotidiano respira aflita diante dos desafios crescentes para manter pilares frágeis de uma questionável sociedade baseada na família, na educação e no trabalho.

Se em toda parte há sinais de uma sociabilidade gradativamente mais crítica, há a necessidade de se entender as particularidades da crise para cada lugar e também de se buscar um fundamento teórico que possa de fato apresentar uma compreensão mais aprofundada do mundo em que vivemos. Mas será que a Geografia pode dar conta dessa tarefa? Não estará ela mesma em crise diante de tantos desafios?

Apontar uma crise da Geografia não é novidade. Em fins dos anos 1970, o esforço de renovação crítica da disciplina partia de semelhante constatação. Milton Santos, em Por uma geografia nova ${ }^{2}$, especificava uma crise da Geografia tradicional, vista como eminentemente empiricista e descritiva, que desde o pós-guerra se deparava com sua insuficiência metodológica para dar respostas às exigências de transformação social postas pela sociedade para a ciência. O movimento inspirado na Geografia Ativa francesa motivava uma geração de geógrafos brasileiros que talvez não chegassem a compor uma unidade de fato. Outras formas de renovação por "novos paradigmas" como a quantificação e a teoria dos sistemas também se voltavam à Geografia tradicional, reforçando sua crise, mas indicando "propostas de renovação múltiplas e divergentes"3.

Armando Corrêa da Silva, por exemplo, tratava de uma crise de cultura levando à crise da Geografia, dos geógrafos, da universidade e do ensino, observando a emergência de uma espécie de contracultura adequada à renovação disciplinar:

No âmbito da cultura da crise a Geografia Crítica põe-se como o modo possível de opor-se ao poder existente. (...) A Geografia Teórica põe-se como a contrapartida dialética necessária da crítica da Geografia Empírica, concreta e abstrata. Mas é apenas um momento da retomada da totalidade, no fazer-se uma Geografia teórica e prática, capaz de explicar e transformar o real ${ }^{4}$.
Cássio Arruda Boechat

Universidade Federal do Espírito Santo. Pesquisa financiada pela FAPES

cassio.boechat@ufes.br

Fábio Teixeira Pitta

Lateinamerika Institut, Freie Universität, Berlim, Alemanha. Pesquisa financiada pela FAPESP pitta.fabio@gmail.com

Ana Carolina Gonçalves Leite Universidade Federal de Pernambuco carolinavecchia@gmail.com

Erick Gabriel Jones Kluck Universidade de São Paulo. Pesquisa financiada pela CAPES erick@usp.br

Daniel Manzione Giavarotti Programa de Pós-graduação em Geografia Humana da USP. manzione79@gmail.com

Allan Rodrigo de Campos Silva Programa de Pós-graduação em Geografia Humana da USP. allanpos@gmail.com

Carlos de Almeida Toledo Universidade de São Paulo catoledo@usp.br

1 - Ver BOECHAT, C. A.; TOLEDO, C. A. \& PITTA, F. T. Land grabbing e crise do capital: possíveis interseções dos debates. In: Geographia, v. 19, n. 40, UFF, maio-agosto, 2017, p. 75-91.

2 - SANTOS, M. Por uma geografia nova: Da crítica da geografia a uma geografia crítica. 6ed. São Paulo: Editora da Universidade de São Paulo, 2008 [1978- 1a. ed.].

Continua...

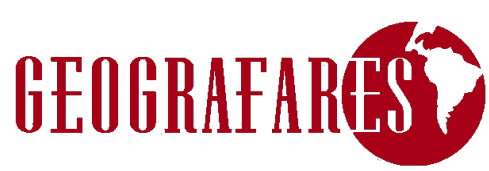

Revista do Programa de Pós-Graduação em Geografia e do Departamento de Geografia da UFES

Janeiro-Junho, 2019 ISSN 2175-3709 


\section{Genorafaress}

Revista do Programa de Pós-Graduação em Geografia e do Departamento de Geografia da UFES

Janeiro-Junho, 2019

ISSN 2175-3709

3 - MORAES, A. C. R. e COSTA, W. M. da. A geografia e o processo de valorização do espaço. In: SANTOS, M. (org.) Novos rumos da geografia brasileira. 4. ed. São Paulo: Hucitec, 1996 [1981 - 1a. ed.], p. 112.

4 - SILVA, A. C. da. Contribuição à crítica da crise da geografia. In: SANTOS, M. (org.) Novos rumos da geografia brasileira. 4. ed. São Paulo: Hucitec, 1996 [1981 1a. ed.], p. 18.

5 - SANTOS, M. Alguns problemas atuais da contribuição marxista à geografia. In: SANTOS, M. (org.) Novos rumos da geografia brasileira. 4. ed. São Paulo: Hucitec, 1996 [1981 1a. ed.], p. 131-133.

6 - SEABRA, M. F. G. Crise econômico-social e a realidade brasileira. In: SANTOS, M. (org.) Novos rumos da geografia brasileira. 4. ed. São Paulo: Hucitec, 1996 [1981 1a. ed.], p. 166.

7 - Agradecemos a David Harvey e a Michael Roberts a autorização dada, por meio de e-mails, para a tradução e publicação dos referidos textos.
A "retomada da totalidade" e a "contrapartida dialética" sugerem um encaminhamento da Geografia para uma literatura marxista, embora também bastante variada, sugerindo a busca de uma síntese entre teoria e prática na qual à crítica se colocaria a tarefa de transformação social, a rigor uma crítica modernizadora. No entanto, o próprio Milton Santos ${ }^{5}$ apontava problemas para o atrelamento completo desse esforço de crítica ao marxismo da época, preocupando-se com a postura dedutiva e com certo dogmatismo que congelava conceitos, bloqueando sua auto-crítica.

O contexto dessa renovação era o esgotamento do assim chamado "milagre econômico" e, com ele, o do próprio regime ditatorial que conduzia a "marcha forçada", levando segundo as palavras de Manoel Seabra ${ }^{6}$ a uma "crise econômico-social" marcada pela "redivisão territorial do trabalho" devido às novas formas de ser da indústria e do controle monopolista mundial.

Essa breve recapitulação pode nos levar a pensar certa relação entre a crise "econômico-social" e a crise epistemológica. No entanto, a crise que era apontada como sendo da Geografia tradicional indicava a necessidade de uma postura nova da Geografia em buscar dar respostas e propostas para a modernização retardatária, no caso brasileiro. Vislumbrava-se a possibilidade do marxismo da luta de classes fornecer algumas delas, embora algumas ressalvas a essa atrelamento completo da Geografia crítica a uma Geografia marxista fossem feitas in loco.

Embora estejamos vivenciando novamente (ou ainda) o fenômeno da "crise econômico-social" batendo à nossa porta, devemos nos questionar o que ele tem de repetição para o daqueles anos finais dos 1970 e início dos 1980 e se não se faz presente uma crise da própria Geografia crítica, malgrado sua própria questionável unidade. Podemos começar enfrentando essas questões nos perguntando se existe uma teoria da crise marxista. Com isso, podemos refletir sobre o que uniria a crise dos anos 1970/1980 com a atual e como ela poderia ser enfrentada teoricamente. No âmbito da Geografia, o lugar dessa suposta "teoria da crise" poderia nos levar a uma peculiar qualificação do olhar para as particularidades analisadas. Em poucas palavras, colocamos a seguinte pergunta: existe e faz sentido promover uma Geografia da crise?

A nossa porta de entrada aqui é o debate traduzido para o português entre David Harvey e Michael Roberts ${ }^{7}$ sobre a existência ou não na obra de K. Marx de uma "teoria da crise", publicado inicialmente na coletânia The Great Financial Meltdown, organizada por Turan Subasat (Northampton, EUA: Edward Elgar Publishing, 2016).

David Harvey é, desde os anos 1970 com a publicação de The Limits to Capital, um dos expoentes de uma Geografia crítica explicitamente marxista. Na obra em questão, o debate sobre os níveis diversos de expressão da crise do capital é articulado à teoria do imperialismo de Lenin e de Luxemburgo, algo que iria culmi- 
nar na sua formulação sobre o "ajuste espacial"8 e sobre os processos de desvalorização, entabulados numa vasta obra que tem imensa visibilidade, não apenas no interior da Geografia. Desse modo, oscilando entre conceber a crise a partir da sobreacumulação de capital ou a partir do subconsumo das massas e buscando analisar suas implicações mais amplas, Harvey tem se debruçado longamente sobre o tema.

Em "Teoria da crise e a queda da taxa de lucro", os termos do debate sobre o estatuto da teoria da crise na obra de K. Marx são claramente expostos, com uma tomada de posição do geógrafo. D. Harvey deixa claro que a questão é quanto à importância a ser dada ao capítulo 13 do Livro 3 d'O capital, no qual Marx expõe a teoria da queda tendencial da taxa de lucro. Nesse capítulo, o pensador alemão discorre sobre o impacto do aumento da composição orgânica do capital, que, ao ampliar a proporção do capital constante sobre o variável, tende a corroer as bases de extração de mais-valia e, com isso, limitar a taxa de lucro. Para Harvey, haveria certas objeções a serem postas a esse princípio dinâmico visto por alguns como o fundamento essencial das crises no capitalismo.

Para começar, de acordo com estudiosos alemães que estão revendo os manuscritos originais, recuperados por Harvey, até mesmo o título e a ordem dos capítulos teriam sido modificados por F. Engels, que procedeu à edição póstuma do Livro, conferindo uma centralidade e importância para a teoria da queda tendencial da taxa de lucro que o próprio Marx não teria dado.

Além disso, o autor ressalta o papel de tendências contrariantes, expostas no original nos capítulos subsequentes ao que expõe a lei enquanto tal. $\mathrm{O}$ aumento da taxa de exploração, o barateamento de componentes do capital constante, a associação de capitais em sociedades de ações e o papel do comércio exterior seriam algumas dessas tendências a impedir que aquela queda inicial da taxa de lucro viesse a se efetivar. Desse modo, Harvey coloca em questão a própria consistência lógica da explicação da queda da lucratividade, abrindo, então, caminho para buscar diversas outras explicações para a existência das crises no capitalismo. Ademais, recuperando as pesquisas recentes de adeptos da teoria da crise, o geógrafo inglês questiona a possibilidade de se averiguar empiricamente com dados os movimentos da taxa de lucro num nível global, observando a produção de dados estatísticos como extremamente problemática.

O autor aponta, com isso, para uma multiplicidade de causas, ao invés de uma causa única circundada ao aumento da produtividade do trabalho. Cita, por exemplo, os movimentos da monopolização, a queda da demanda efetiva decorrente da dificuldade da massa da população em consumir suficientemente e o papel distorcivo do capital financeiro em modificar a concorrência e conduzir a ascensões e derrocadas de mercados.

Desse modo, Harvey parece ampliar as possibilidades de explicação para as causas das crises no capitalismo, criticando a expli-
8 - Ver HARVEY, D. O novo imperialismo. 7 ed. São Paulo: Edições Loyola, 2013. e HARVEY, D. A produção capitalista do espaço. São Paulo: Annablume, 2005. 


\section{GenGrafaress}

Revista do Programa de Pós-Graduação em Geografia e do Departamento de Geografia da UFES

Janeiro-Junho, 2019 ISSN 2175-3709 cação em torno da queda tendencial da taxa de lucro, que é apontada por ele como sendo raramente aquela que, de fato, explicaria as crises reais. Haveria, assim, a necessidade de olhar para cada caso em sua particularidade, observando seus impactos para as realidades distintas em que ocorrem.

Um dos adeptos da teoria da crise em torno da formulação marxiana da queda tendencial da taxa de lucro, diretamente citado e criticado por D. Harvey em seu artigo, é o economista inglês Michael Roberts, que elabora uma réplica ao geógrafo em "Monocausalidade e teoria da crise".

De início, o debate se ergue em torno da própria autoridade textual, questionada por autores como Michael Heinrich em torno das edições $M E G A$ que estão relendo os manuscritos de Marx e propondo reinterpretações. É de se lembrar, antes de mais, que a teoria da crise não chegou a fazer parte do mainstream do marxismo tradicional, sendo continuamente ignorada ou tendo sua importância diminuída. Assim, a postura de Heinrich, ao gosto do que Harvey advoga, não seria exatamente uma novidade. $\mathrm{O}$ que Roberts contrapõe, ao contrário, é que mesmo entre os autores da $M E G A$ há controvérsias. F. Moseley, por exemplo, é um dos que vêm elogiando o esforço e a qualidade da edição dos manuscritos feita por Engels.

Entretanto, a querela que se desenvolve é trazida pelo economista inglês para as questões do primado da totalidade e da abstração real e para a necessidade de uma teorização. Desse modo, Roberts afirma que a proposta de uma visão mais conjuntural de que cada crise teria uma explicação, como parece ser a conclusão de Harvey, incorreria num ecletismo que, em última instância, seria o abandono de qualquer teoria da crise. Retomando G. Carchedi, o autor afirma que se cada crise tem uma explicação diferente e as crises são recorrentes, pode-se com uma busca de variadas explicações indicar as causas particulares mas não se pode explicar sua recorrência. A causa de fundo, ou subjacente, seria, para os autores, a queda tendencial da taxa de lucro.

Todavia, diferente do que Harvey parece apontar para esses defensores da teoria marxiana da crise, o papel das tendências contrariantes não é desprezado. Para Roberts, o estatuto dessas contratendências parece ser tão importante como o da lei enquanto tal, justificando pela ação delas a recorrência ou o caráter cíclico das crises reais do capitalismo. Embora busquem distinguir tais contratendências entre aquelas que agem internamente na operação da lei - como o aumento da taxa de exploração e o barateamento do capital constante - e as que agem externamente no âmbito do "capital em geral" - como a taxação, o comércio externo e etc -, é interessante a incorporação de elementos que, segundo Harvey, seriam ignorados, como a financeirização e a monopolização em processo.

No que tange à qualidade do referido caráter cíclico das crises, elas são apontadas como um desequilíbrio constante da reprodu- 
ção social capitalista e não como uma retomada de qualquer noção neoclássica de equilíbrio. Ainda assim, é de se ressaltar a existência de alguma formulação de crise cíclica, mesmo entre esses adeptos da teoria marxiana da crise, o que talvez seja o que os diferencie de outras formulações mais radicais.

Por fim, há nesses autores, capitaneados aqui por M. Roberts, um esforço tremendo em levantar, organizar e analisar dados estatísticos, visando um acompanhamento da evolução da taxa de lucro nas principais economias do mundo. Esse procedimento, questionado por Harvey como incoerente e mesmo impossível, revela uma preocupação em tentar "provar" empiricamente a teoria da crise. Bem ao gosto de uma perspectiva cientificista, trata-se de uma forma de promover a teoria da crise que se mostrará bastante distinta das de outros adeptos da mesma.

$$
* *
$$

A radicalização da teoria da crise pode ser encontrada no questionamento da reprodução social das categorias mais elementares da sociedade capitalista, aprofundando um aspecto que permite por em questão o caráter cíclico da crise. Essa radicalização pode ser encontrada em textos como os de Robert Kurz e de Roswitha Scholz ${ }^{9}$, que abrem caminhos para uma reinterpretação profunda da obra de K. Marx, sem exatamente abandonar a teoria do valor e a da crise.

O longo ensaio de Robert Kurz, publicado inicialmente em 1995, intitulado "A ascensão do dinheiro aos céus", aborda como questão central a dessubstancialização do dinheiro. Tal dessubstancialização (no sentido essencial do valor), ocorrida no processo social, não impede, no entanto, que a forma dinheiro, pela qual se exerce boa parte da sociabilidade moderna, continue a existir. $\mathrm{O}$ mesmo vale para o trabalho, como demonstra Kurz, um dos pilares da forma de mediação moderna, e ao mesmo tempo, cerne da contraditória substancialização e dessubstancialização do dinheiro. Segundo ele, o processo social geral da modernização sob o qual trabalho e dinheiro são constituídos, também promove essencialmente o descolamento entre ambos. Assim, por exemplo, para a produção real de mercadorias há uma dependência cada vez maior do capital portador de juros, os créditos, que ganham dimensões astronômicas no qual de forma crescente o Estado, com capital fictício, assume cada vez mais um papel central na manutenção de um sistema social falido.

Para realizar tal percurso, o autor retoma o Livro 3 d'O capital, mostrando a conformação do capital portador de juros e do crédito como processos de gradativo distanciamento entre o circuito do dinheiro e o circuito da mercadoria, sendo que é na produção das mercadorias pela exploração do trabalho que o valor pode se valorizar e, com isso, substancializar o dinheiro. Buscando uma explicação atualizada e aprofundada do chamado capital fictício, Kurz aborda teoricamente as possibilidades do dinheiro não passar por processos de valorização, em circuitos de endividamento cada vez mais complexos. Há aqui uma interpretação inovadora das formas
9-Agradecemos a autorização dada pessoalmente por Roswitha Scholz para a tradução e publicação dos textos e aquela dada por Boaventura Antunes para que revisássemos as traduções feitas por ele e pelo coletivo Obeco dos textos originais para o português de Portugal. 


\section{GenGrafaress}

Revista do Programa de Pós-Graduação em Geografia e do Departamento de Geografia da UFES

Janeiro-Junho, 2019 ISSN 2175-3709 do capital fictício como se tornando centrais numa reprodução social tornada crítica, sobretudo pelo processo de expulsão do trabalho vivo dos processos produtivos de valor, resultado do aumento da composição orgânica do capital.

Assim, a teoria da crise, em torno das implicações mais amplas do aumento da produtividade, atreladas aos mecanismos desdobrados das finanças embrenhadas na dívida pública, é colocada adiante. A explosiva simultaneidade dos impactos da Terceira Revolução Industrial, a partir dos anos 1970, na promoção do aumento da composição orgânica do capital, com as formas de suposta valorização do dinheiro permitem requalificar o capital financeiro como capital fictício.

Ao contrário do que outros adeptos da mesma formulação teórica de base, a crise do trabalho e a crise de valorização que se afirmam não permitem conceber mais movimentos cíclicos de crise, mas tão somente um contínuo aprofundamento da dessubstancialização, a qual apenas políticas de gestão de crise podem parcialmente mitigar seus efeitos mais superficiais.

Outro longo ensaio que contribui para essa discussão é o de Roswitha Scholz, “Cristóvão Colombo Forever!", publicado originalmente pela Revista EXIT! em 2016 e cuja tradução portuguesa feita por Boaventura Antunes nesse mesmo ano adaptamos para o português brasileiro, além de substituir citações e referências de algumas obras já publicadas no Brasil.

A autora trata nele do impulso conquistado contemporaneamente por inúmeras teorias da colonização nas discussões da esquerda, sobretudo depois da chamada crise de 2008. De maneira abrangente, essas teorias dialogam com uma interpretação clássica da tese luxemburguista de que o capitalismo necessita da permanente incorporação do que lhe é externo para continuar se reproduzindo. Argumenta-se, portanto, que a acumulação primitiva não teria ficado restrita aos primórdios do capitalismo, recriando-se continuamente como condição para a acumulação. Entre os objetos de sua crítica, Scholz toma alguns trabalhos de Silvia Federici e Klaus Dörre, pela proeminência dos mesmos não apenas na Alemanha, tratando, todavia, de matizar as diferenças que possuem, com destaque para a abordagem feminista perseguida por Federici, enquanto a orientação de Dörre se mantém mais próxima do marxismo tradicional. Sua crítica a Dörre e Federici não se furta a discutir as perspectivas emancipadoras defendidas por ambos, de modo a explicitar como o próprio entendimento do processo histórico em curso apresentada por eles guarda, de forma subjacente, certas perspectivas "emancipadoras" e organizativas que tendem a convergir, a despeito das diferenças.

Contrapondo-se à leitura que atribui à contínua acumulação primitiva a posição de sustentáculo da reprodução do capital, a autora chama nossa atenção para os desdobramentos de uma relação social que tem como fundamento a contradição em processo, segundo os termos sugeridos por Marx nos Grundrisse. Nesse sen- 
tido, Roswitha Scholz vai delineando um contexto histórico atual fundamentalmente diferente daquele que caracterizou a acumulação primitiva ou as modernizações retardatárias, permitindo-lhe localizar os aparentes impulsos de "colonização" que pululam à escala mundial, dado o caráter globalizado da economia, como expressões de uma crise fundamental do capital e não como a formação de novos regimes de acumulação, como querem fazer crer Federici e Dörre.

Tomar a contradição em processo como ponto de partida significa conceber a irreversibilidade do processo histórico determinado pela acumulação de capital, a qual mina seu próprio fundamento na forma do incremento da composição orgânica e a descartabilidade ampliada de trabalho vivo no processo produtivo. Como desdobramento distingue, ainda, no âmbito da totalidade concreta, as guerras civis mundiais conformando o atual ordenamento mundial cujo horizonte já não se define como realização do projeto imperialista e passa, cada vez mais, pela gestão de territórios desconectados em permanente estado de exceção, todavia globalizados.

Tudo isso, Roswhita Scholz discute não deixando que sua argumentação se restrinja à questão da contradição em processo. Sua perspectiva trata, ao contrário, de evidenciar as diferenças concernentes à crítica do valor-dissociação, entendida como contexto dinâmico de base. Assim, em seu ensaio leva em conta as diferentes disparidades sociais (econômicas, étnico-raciais, de gênero e antissemitas) engendradas atualmente, considerando-as em suas qualidades próprias para pensar o processo de desmantelamento social que está no foco da sua reflexão, recusando a aplicação de uma lógica identitária, tal como faz notadamente Federici, mas também Dörre de maneira indireta.

Vemos, com isso, dois autores, Robert Kurz e Roswitha Scholz que abrem caminhos profícuos para uma interpretação inovadora e aprofundada da teoria da crise que, numa escala de análise global, permitem ainda uma interessante perspectiva de autocrítica, na medida em que contestam abordagens nacionalistas, modernizantes e androcêntricas presentes também em formulações de esquerda e marxistas.

Um grande esforço de desdobramento das implicações acima apontadas, particularizando análises para tratar de uma realidade mais próxima à que vivemos, vem sendo feito por diversos autores, ao seu modo.

Em "Noites brancas", Marildo Menegat faz uma análise do processo de militarização recente da sociedade brasileira. $\mathrm{O}$ autor apresenta uma leitura relevante sobre a dinâmica da crise social brasileira como resultado de um processo complexo e de vários níveis. Por um lado, o entendimento da geopolítica brasileira como cooperação subordinada propõe uma releitura da orientação ideológica dos militares no Brasil em direção ao liberalismo. Já a escala urbana é apresentada como território do exercício da barbárie, 


\section{GenGrafaress}

Revista do Programa de Pós-Graduação em Geografia e do Departamento de Geografia da UFES

Janeiro-Junho, 2019 ISSN 2175-3709 da qual o exército toma para a si o papel de gestor. Na experiência histórica a missão brasileira no Haiti é apresentada como laboratório de práticas de gestão social da crise que ora o país vivencia.

O texto apresenta uma leitura bastante completa das análises correntes da crise social brasileira postas a luz de uma interpretação teórica inovadora, situando a crise política e social brasileira no quadro mais amplo da do colapso da modernização e da crise da sociedade do trabalho. Desse modo, revela possuir uma inspiração de fundo na obra de Robert Kurz, atrelando-se, assim, à sua peculiar interpretação e desenvolvimento da teoria da crise.

Outra interessante proposta vem de Maurílio Lima Botelho, em "Superacumulação e colapso do capitalismo no Brasil em retrospectiva". Invertendo o habitual individualismo metodológico, aprisionado entre o nacionalismo e personalismo, o autor tensiona com as explicações acerca da crise brasileira, postas em perspectiva a partir de um entendimento da dinâmica de crise do capitalismo global contemporâneo. A partir de um entendimento determinado da teoria da crise do capitalismo, o quadro nacional é agora apresentado no seu encurralamento histórico, próprio ao colapso do processo de modernização. Acompanhando a leitura marxista do fetichismo da mercadoria, as ações políticas são situadas no terreno da prática reificada: dos mais poderosos ao dito incompetente, líderes políticos fazem a história, mas não a fazem como querem.

Inicialmente temos uma análise da crise do capitalismo brasileiro em sua correlação com o crescimento ficcionalizado da economia brasileira até 2014 , logo seguido de uma recessão que surgia para cobrar a conta daquele crescimento ilusório. Caminhando em direção à uma teoria da crise, em um segundo momento, temos uma formulação acerca da superprodutividade de capitais como fundamento geral do capitalismo contemporâneo, temperado pela constituição histórica periférica da formação brasileira. $\mathrm{O}$ espetáculo do crescimento brasileiro é posto assim sob a luz negra do boom fictício das commodities que deságua na recessão derivada do excesso de capital fixo improdutivo, com seus respectivos impactos para o serviço público, a renda e o nível de emprego. Por fim, o autor apresenta uma leitura histórica do processo de crise brasileiro como manifestação de uma modernização retardatária, já esgotada desde meados do século XX.

Sob este prisma, os desdobramentos recentes na economia nacional brasileira surgem sob a figura de uma nova forma de concorrência, global e imediata, cuja lógica do saque e da terra arrasada reiteram a atomização dos indivíduos e barbarização do capitalismo global, transfronteiriço e cada vez mais restrito em suas possibilidades de valorização fictícia.

$$
* * * *
$$

O que já se vislumbrava com o artigo de Maurílio L. Botelho, professor de Geografia da UFRRJ, como desdobramento da teoria da crise, particularizada pela crítica do valor-dissociação, impli- 
cando numa renovada produção dentro da Geografia brasileira, encontra interessante expressão na produção de jovens pesquisadores.

Em seu artigo "Apontamentos sobre experiências femininas de migrações e trabalho", Clara Lemme Ribeiro parte do debate sobre a chamada feminização das migrações desde o início distanciando-se dos argumentos que ressaltam apenas o "pioneirismo feminino" nas migrações ou a formação de processos migratórios majoritariamente de mulheres. Compreender o processo passa necessariamente por discutir também o que acontece com o emprego masculino e os papéis assumidos por homens e mulheres no interior das famílias, ou seja, no âmbito reprodutivo, contemporaneamente. Para a autora, ambos os processos só podem ser entendidos de fato, para além de sua apreensão fenomênica, seja quantitativa ou qualitativa, mediante uma discussão acerca do fundamento dos mesmos: a crise do trabalho. Vai sendo apresentada, assim, uma leitura sobre as condições contemporâneas de reprodução capitalista que passa, ainda, pela análise detida da migração de bolivianos para o trabalho em oficinas de costura na cidade de São Paulo. Não se deixando deter no repertório mais corriqueiro sobre o tema, qual seja, o problema da reestruturação produtiva, do trabalho análogo ao de escravo, da superexploração do trabalho ou até mesmo da desigualdade de remuneração entre homens e mulheres nas confecções, o cerne da sua investigação trata de compreender certa fusão entre produção e reprodução que toca as oficinas de costura como momento da referida crise.

Retomando os argumentos de Roswhita Scholz, Ribeiro rejeita as interpretações que assumem como pressuposto a possibilidade sempre renovada de acumulação, mesmo que "primitiva", e relaciona precarização e flexibilização com superfluidade do trabalho no contexto de crise. Ultrapassa, contudo, essa análise para encontrar tais relações de trabalho também como um acirramento da dissociação entre os gêneros, tão fundamental quanto a mediação do valor para a reprodução das relações capitalistas.

$\mathrm{O}$ artigo de Artur Attarian Camarero, "Identidade e migração armênia: apontamentos e críticas”, aborda de forma importante e crítica a questão da identidade armênia, o patriarcado e a reprodução do trabalho deste grupo particular de migrantes. Para tanto, realiza um apanhado histórico e teórico além de observações de campo (efetivado em 2016).

As experiências migratórias desses grupos armênios para o estado de São Paulo no início do século XX são apresentadas em minúcias que vão desde as relações de trabalho (ligadas ao ramo dos calçados) até as formas de sociabilidade intrafamiliares, que ao olhar de outros autores que estudaram a temática constituiria a chamada identidade armênia, pelos quais Camarero, no entanto, consegue de maneira ímpar estabelecer uma crítica radical, entendendo tal sociabilidade como constitutiva da totalidade concreta não dissociada da relação capital. Não menos importante é o tra-

\section{gengrafaress}

Revista do Programa de Pós-Graduação em Geografia e do Departamento de Geografia da UFES

Janeiro-Junho, 2019 ISSN 2175-3709 


\section{BenGRAFARESS}

Revista do Programa de Pós-Graduação em Geografia e do Departamento de Geografia da UFES

Janeiro-Junho, 2019 ISSN 2175-3709 tamento que dá a questão do jovem, filho de imigrantes, e suas perspectivas diante das transformações geracionais imbricadas nas mudanças recentes do capital como componente importante da reprodução da sociabilidade armênia. O mesmo empenho crítico utilizou ao discorrer sobre a sua experiência em campo, quando esteve na Armênia, na qual pode conversar, vivenciar e observar de muito perto todo o conjunto de relações contemporâneas estabelecidas, principalmente aquelas associadas à mulher, na sociedade armênia.

Assim, a base da sua crítica retoma aquelas realizadas por Jean Paul de Gaudemar e Roswitha Scholz, acima citada, respectivamente no que toca à mobilidade do trabalho e à questão do valor-dissociação, tratando da forma social de reprodução do trabalho sob o capital no contexto de migração.

$\mathrm{O}$ artigo de Pedro Benetazzo Serrer, "Planejamento estatal do turismo na Chapada Diamantina como administração da crise", apresenta a transformação de uma região devotada ao garimpo de diamantes ao longo dos séculos XIX e XX em atração turística impulsionada pelos esforços planejadores do Estado a partir da década de 1970.

Discutindo a atuação da empresa estatal Bahiatursa, a participação de voluntários dos Peace Corps, alguns deles responsáveis pelo processo de patrimonialização do Parque Nacional da Chapada Diamantina, bem como a chegada de trabalhadores complexos das grandes capitais brasileiras como Salvador e Rio de Janeiro, Serrer vai articulando transformações empíricas observadas à escala local sem perder de vista a relação que estas estabelecem com a totalidade fragmentária e contraditória do capital. Por meio deste percurso, o artigo oferece ao leitor uma análise dos desdobramentos destas transformações na própria forma de ser do Estado Brasileiro e o papel distinto que este foi adquirindo ao longo da modernização retardatária brasileira até sua crise, a partir de uma interlocução crítica com o sociólogo Francisco de Oliveira. Desdobra a partir daí como tais transformações foram igualmente determinantes no lugar ocupado pela própria Chapada Diamantina na divisão territorial brasileira, porque relativamente metropolizada, assim como a população diminuta que por lá ainda vive, a qual deixou de ser uma pré-classe no processo de modernização nacional para se tornar uma pós-classe, vivendo uma mobilidade do trabalho que envolve o garimpo manual na serra, tornado ilegal pelo processo de patrimonialização, e o oferecimento de serviços na cidade direta ou indiretamente conectados ao turismo, o que igualmente envolve o trabalho com o tráfico de drogas. Por fim, ao ter em conta a dinâmica temporal do próprio capital, Pedro Serrer reconhece a historicidade do Estado e da própria prática turística, discutindo a relação entre ambos como uma conjunção própria à crise do trabalho e à ficcionalização do capital.

No artigo "A expansão na disponibilidade de crédito Pronaf às comunidades quilombolas do Vale do Ribeira/SP 
como expressão da crise imanente do Capital", Cecilia Cruz Vecina apreende o Programa Nacional de Agricultura Familiar (PRONAF) em mediação com a formulação de crise fundamental de acumulação do capital de Robert Kurz e Roswitha Scholz. Após o início do chamado "boom das commodities", em 2002-2003, os governos do Partido dos Trabalhadores expandiram de forma significativa o crédito subsidiado para a pequena produção agrícola, garantindo, inclusive via outros programas, a realização das mercadorias então produzidas. A autora, assim, não trata tal programa como distribuição de riqueza produzida socialmente, mas por meio da crítica dialética da sociedade, insere o mesmo em um contexto histórico particular do desenvolvimento da sociedade capitalista, pautado pela criação fictícia de dinheiro e pela expulsão do trabalho do processo produtivo, configurando uma crise do próprio trabalho como categoria capitalista historicamente determinada.

O ensaio, por sua vez, não deduz dessa apreensão mais geral de totalidade a realidade estudada, a saber, comunidades quilombolas do Vale do Ribeira do Estado de São Paulo, mas busca, na particularidade destas comunidades, compreender o que significam as comunidades deterem acesso a pequenas parcelas de terra, insuficiente por si para permanecerem nas mesmas (no período histórico estudado), estando de certa maneira ali ao mesmo tempo constritas e expropriadas, dependendo de produzirem de forma subsidiada para o mercado. Após o advento da crise econômica brasileira com o fim da alta dos preços das commodities (2012) e com os consequentes cortes nos programas estatais a partir do ajuste fiscal de 2015 (incluído aqui o PRONAF), as comunidades se viram endividadas e inadimplentes. Ou seja, apesar do acesso à terra, o que recolocaria a questão acerca de uma reposição eterna de uma acumulação primitiva que seria supostamente necessária para o capital acumular, a autora se questiona o que significa a presente crise econômica brasileira a partir da situação do quilombola que não recebe nem salário, nem renda da terra, produz de forma subsidiada para o mercado e nem assim o capital nacional que adquire tais mercadorias logra se reproduzir ampliadamente. Ainda, após os cortes supracitados, as dívidas dos quilombolas passaram a ser cobradas (de maneira irregular, como mostra o artigo) e mesmo assim a economia brasileira continua em sua situação de crise. Desta forma, a autora levanta a questão do que significaria falar de acumulação de capital hoje e do acesso à terra como meio de produção em tal contexto histórico de crise do capital a nível mundial.

A compilação de textos assim proposta permite um caminho por dentro da análise da teoria marxiana da crise e suas implicações para a Geografia e para além dela. Como breve balanço preliminar e provisório, podemos observar uma tensa unidade que dificilmente corrobora uma vertente nova, positivamente criada para a disciplina, em torno de uma suposta Geografia da crise.

No entanto, a necessidade de se pensar a crise dos fundamentos

\section{GenGrafariss \\ Revista do Programa de Pós-Graduação em Geografia e do Departamento de Geografia da UFES \\ Janeiro-Junho, 2019 ISSN 2175-3709}




\section{GEOGRAFARES}

Revista do Programa de Pós-Graduação em Geografia e do Departamento de Geografia da UFES

Janeiro-Junho, 2019

ISSN 2175-3709 mais elementares da sociedade mundial produtora de mercadorias exige um esforço de teorização e de análises que vai além, nesse apanhado, de casos conjunturais e de perspectivas para se corrigir o curso da modernização. Nesse sentido, ainda que a contragosto, algo como uma Geografia da crise surge efetivamente de diversos estudos que tem encontrado na crítica do valor-dissociação uma postura adequada para enfrentar de maneira autocrítica os desafios de uma sociedade em crise. 